\title{
BMJ Open Fructose intake and risk of gout and hyperuricemia: a systematic review and meta-analysis of prospective cohort studies
}

\author{
Joseph Jamnik, ${ }^{1}$ Sara Rehman, ${ }^{1,2}$ Sonia Blanco Mejia, ${ }^{1,2}$ Russell J de Souza, ${ }^{2,3}$ \\ Tauseef A Khan, ${ }^{1,2}$ Lawrence A Leiter, ${ }^{1,2,4,5,6}$ Thomas M S Wolever, ${ }^{1,2,4,5,6}$ \\ Cyril W C Kendall, ${ }^{1,2,7}$ David J A Jenkins, ${ }^{1,2,4,5,6}$ John L Sievenpiper ${ }^{1,2,5,6}$
}

To cite: Jamnik J, Rehman S, Blanco Mejia S, et al. Fructose intake and risk of gout and hyperuricemia: a systematic review and metaanalysis of prospective cohort studies. BMJ Open 2016;6:e013191. doi:10.1136/bmjopen-2016013191

- Prepublication history and additional material is available. To view please visit the journal (http://dx.doi.org/ 10.1136/bmjopen-2016013191).

Received 9 July 2016 Revised 25 August 2016 Accepted 5 September 2016

CrossMark

For numbered affiliations see end of article.

Correspondence to Dr John L Sievenpiper; john.sievenpiper@utoronto.ca

\section{ABSTRACT}

Background: The prevalence of hyperuricemia and gout has increased in recent decades. The role of dietary fructose in the development of these conditions remains unclear.

Objective: To conduct a systematic review and metaanalysis of prospective cohort studies investigating the association fructose consumption with incident gout and hyperuricemia.

Design: MEDLINE, EMBASE and the Cochrane Library were searched (through September 2015). We included prospective cohort studies that assessed fructose consumption and incident gout or hyperuricemia. 2 independent reviewers extracted relevant data and assessed study quality using the Newcastle-Ottawa Scale. We pooled natural-log transformed risk ratios (RRs) using the generic inverse variance method. Interstudy heterogeneity was assessed (Cochran $Q$ statistic) and quantified (I ${ }^{2}$ statistic). The overall quality of the evidence was assessed using the Grading of Recommendations Assessment, Development and Evaluation (GRADE) approach.

Results: 2 studies involving 125299 participants and 1533 cases of incident gout assessed the association between fructose consumption and incident gout over an average of 17 years of followup. No eligible studies assessed incident hyperuricemia as an outcome. Fructose consumption was associated with an increase in the risk of gout (RR=1.62, $95 \% \mathrm{Cl} 1.28$ to $2.03, p<0.0001$ ) with no evidence of interstudy heterogeneity $\left(I^{2}=0 \%, p=0.33\right)$ when comparing the highest $(>11.8 \%$ to $>11.9 \%$ total energy) and lowest ( $<6.9 \%$ to $<7.5 \%$ total energy) quantiles of consumption.

Limitations: Despite a dose-response gradient, the overall quality of evidence as assessed by GRADE was low, due to indirectness. There were only two prospective cohort studies involving predominantly white health professionals that assessed incident gout, and none assessed hyperuricemia.

Conclusions: Fructose consumption was associated with an increased risk of developing gout in predominantly white health professionals. More prospective studies are necessary to understand

\section{Strengths and limitations of this study}

- This systematic review and meta-analysis assessed the overall quality of the evidence using the Grading of Recommendations Assessment, Development and Evaluation (GRADE) approach.

- Large prospective cohort studies that were of high quality and had a long duration of follow-up were included.

- The pooled results showed good consistency (low between-study heterogeneity) and evidence of a dose-response gradient.

- Only two prospective cohort studies with low external generalisability were available for inclusion.

- The observational design of the prospective cohort studies did not allow for causal inferences to be drawn.

better the role of fructose and its food sources in the development of gout and hyperuricemia.

Protocol registration number: NCT01608620.

\section{INTRODUCTION}

Gout is a systemic rheumatic condition characterised by monosodium urate crystal deposition and accumulation around joints. Individuals with gout often experience acute and recurring attacks of arthritis that can affect several joints. ${ }^{1}$ Hyperuricemia or excessive circulating concentrations of urate, the final product of purine metabolism, is a major risk factor for gout and plays a major role in the pathogenesis of this condition. ${ }^{2}$ Chronic hyperuricemia and gout also represent potential risk factors for cardiovascular disease (CVD). ${ }^{3}$ According to the National Health and Nutritional Examination Survey 2007-2008, hyperuricemia affects $>20 \%$ of 
the US population, while $\sim 4 \%$ of American adults have gout. ${ }^{4}$ The prevalence of hyperuricemia and gout has increased in recent decades, ${ }^{4-6}$ suggesting potential environmental triggers. Several lifestyle and dietary factors have been implicated in the development of these conditions, including elevated body mass index (BMI), ${ }^{7}$ alcohol consumption ${ }^{8}$ and high dietary intakes of meat and seafood. ${ }^{9}{ }^{10}$ Recent research has also implicated fructose intake in the pathogenesis of hyperuricemia and gout. ${ }^{11} 12$

Fructose is a monosaccharide found commonly in plants. It is also a major constituent of high-fructose corn syrup (HFCS) in sugar-sweetened beverages (SSBs). ${ }^{13}$ Ecological evidence has shown that the increasing prevalence of hyperuricemia and gout in developed countries has paralleled the increase in consumption of total fructose and HFCS. ${ }^{14}$ The phosphorylation of fructose, unlike the monosaccharide glucose, is understood to facilitate ATP depletion and result in an elevation of circulating uric acid levels. ${ }^{11} 1516$ Animal studies and select trials of acute ingestion of fructose-sweetened beverages have shown that fructose can lead to higher blood concentrations of uric acid. ${ }^{17}{ }^{18}$ However, a meta-analysis of isocaloric substitution trials did not support this association between fructose and serum uric acid. ${ }^{19}$ The role of fructose from all dietary sources as a risk factor for incident hyperuricemia and ultimately gout, therefore, remains unclear. Furthermore, there is a notable lack of meta-analyses of prospective studies assessing the role of dietary fructose in the development of disorders of purine metabolism. The objective of this study was to conduct a systematic review and meta-analysis of prospective cohort studies investigating total fructose consumption and its association with incident hyperuricemia and gout.

\section{METHODS}

This meta-analysis was conducted in accordance with the Cochrane handbook for systematic reviews of interventions $^{20}$ and reported following the Meta-analysis of Observational Studies in Epidemiology (MOOSE) guidelines. ${ }^{21}$ The study protocol was registered at ClinicalTrials. gov (NCT01608620).

\section{Study selection}

We performed a comprehensive search of MEDLINE, EMBASE and the Cochrane Library databases from conception through 22 September 2015. The following search terms were used: 'fructose', 'sucrose', 'sugar', 'honey', 'HFCS', 'gout', 'hyperuricemia' and 'uric acid'. No language restrictions were imposed on the search. The complete search strategy is reported in online supplementary table S1. The electronic search was supplemented by a manual review of article reference lists. Abstracts were considered, and authors were contacted for missing information. We only included prospective cohort studies which assessed the association between total dietary fructose intake and incident hyperuricemia or gout. Studies were considered eligible if cases of gout were ascertained using self-report of a physician diagnosis, while the assessment of hyperuricemia required serum uric acid measurements above study-specific predefined thresholds.

\section{Data extraction}

Studies were reviewed and excluded based on an evaluation of titles and abstracts. Articles that passed this initial screening were then reviewed in full by two independent reviewers (JJ and SR). The following data were extracted from each using a standardised proforma: authorship, year of publication, cohort name, country, sample size, participant characteristics, duration of follow-up, method of dietary assessment, fructose exposure levels, number of incident hyperuricemia/gout cases, covariates included in statistical models and risk ratios (RRs) of hyperuricemia or gout per quantile of fructose intake with $95 \%$ CIs.

\section{Study quality}

Study quality was assessed using the Newcastle-Ottawa Scale (NOS) for Cohort Studies. The NOS for Cohort Studies is a rating scale where points are awarded to studies based on cohort selection, comparability of groups and assessment of outcomes. ${ }^{22}$ Any given study can have a maximum of nine points. In this analysis, studies that received $\geq 6$ points were considered of high quality. Differences in grading between reviewers were resolved by consensus.

\section{Grading of Recommendations Assessment, Development and Evaluation}

The Grading of Recommendations Assessment, Development and Evaluation (GRADE) approach was used to assess the overall quality and strength of evidence. ${ }^{23-35}$ By this approach, the quality of the totality of evidence can be graded as 'very low', 'low', 'moderate' or 'high'. Evidence derived from observational studies receive an initial grade of 'low', while evidence derived from randomised trials receive an initial grade of 'high'. ${ }^{25}$ Scores can be either upgraded or downgraded depending on a number of factors. Scores for observational analyses can be upgraded for a large magnitude of effect $(R R>2$ or $R R<0.5$ in the absence of plausible confounders), dose-response gradient or reasonable evidence of attenuation of the pooled effect estimate by confounders. ${ }^{31}$ Conversely, scores can be downgraded for risk of bias (weight of studies show risk of bias as assessed by low NOS $<6$ ), ${ }^{26}$ inconsistency (substantial unexplained interstudy heterogeneity), $\mathrm{I}^{2}>50 \%,{ }^{29}$ indirectness (presence of factors that limit the generalisability of the results), ${ }^{30}$ imprecision in the pooled risk estimate (the 95\% CI for risk estimates are wide or cross a minimally important difference of $10 \%$ for benefit or harm (RR 0.9-1.1) ), ${ }^{28}$ and publication bias (evidence of small-study effects). ${ }^{27}$

\section{Statistical analysis}

Data analysis was carried out using Review Manager (RevMan, V.5.3; The Nordic Cochrane Centre, The 
Cochrane Collaboration). RRs of extreme quantiles of fructose intake for incident hyperuricemia/gout were natural-log transformed and pooled using the generic inverse variance method. ${ }^{36}$ Although random-effects models are preferred to fixed effects models because of their conservative nature in the presence of residual interstudy heterogeneity, we used fixed effects models as there were too few studies to estimate $\tau^{2}$ reliably. Interstudy heterogeneity was assessed and quantified using the Cochran $\mathrm{Q}$ and $\mathrm{I}^{2}$ statistics, respectively. ${ }^{37}$ The $\mathrm{I}^{2}$ statistic represents the percentage of total variation across studies that is due to between-study heterogeneity, and $\mathrm{I}^{2} \geq 50 \%$ was considered evidence for substantial heterogeneity. ${ }^{20}$ We could not explore sources of heterogeneity by sensitivity analyses or a priori subgroup analyses owing to too few studies. Publication bias also could not be assessed owing to too few studies.

\section{RESULTS}

\section{Search results}

Results of the systematic search and article selection process are shown in figure 1 . Of the 2195 studies initially identified in the literature search, 2171 were excluded on the basis of title and abstract review. The remaining 24 articles were reviewed in full, and 22 were subsequently excluded. A total of two prospective cohort studies were included in this analysis. ${ }^{38} 39$ Both of these studies pertained to fructose intake and incident gout. We did not identify any prospective studies that assessed total fructose intake and its association with incident hyperuricemia.

\section{Study characteristics}

The characteristics of the two prospective cohort studies included in this analysis are presented in table 1 . Both studies investigated cohorts based in the USA and comprised of older, predominantly white (91\% and 95\%), health professionals. Choi $e t a l^{8}$ consisted of 46393 male dentists, optometrists, osteopaths, pharmacists and veterinarians; aged 40-75, from the Health Professionals Follow-up Study. Choi $e t a l^{39}$ investigated a cohort of 78906 female nurses aged 30-55, from the Nurses' Health Study. The follow-up rate for both cohorts exceeded $90 \%$. The women's cohort had a follow-up duration of 22 years, ${ }^{39}$ while the male cohort was followed for 12 years. ${ }^{38}$ Both studies received six points on the NOS, indicating that they were of high quality. All 125299 participants across both studies were free of gout at baseline, and a total of 1533 confirmed cases of incident gout (755 men, 778 women) were identified.

Methods for collecting dietary and health information were similar between studies. Validated food frequency questionnaires (FFQs) of over 130 different foods and beverages were completed every 4 years. Corresponding nutrient values were derived from US Department of Agriculture Sources and supplemented by manufacturers. Total fructose intake, defined as fructose plus half the intake of sucrose, was assessed in both studies. Median fructose intake was $\sim 7.2 \%$ of total energy in the lowest quantiles of intake and $\sim 11.9 \%$ of total energy in the highest quantiles of intake. ${ }^{38}{ }^{39}$ In the prospective study of the Health Professionals Follow-up Study, the main dietary sources of total monosaccharide fructose were orange juice $(15.9 \%)$, SSBs $(15.5 \%)$, apples $(14.5 \%)$, raisins $(5.2 \%)$ and oranges $(3.2 \%){ }^{38}$

Information regarding weight, medications and medical conditions (including gout) was collected at baseline and every 2 years following for the duration of both studies. Participants who reported physician-diagnosed incident gout were sent a supplementary questionnaire based on the American College of Rheumatology gout survey criteria. ${ }^{40}$ To meet the end point of the study, participants needed $\geq 6$ symptoms out of a possible 11 . The response rate of the supplementary survey was $\sim 80 \%$ for both cohorts. Both studies adjusted for the critical confounders of age, BMI, total energy intake and alcohol consumption (each study was conducted in a single sex, so adjustment for sex was not necessary). Additional adjustments were made for diuretic use, history of hypertension, history of renal failure, menopause status, use of hormone therapy; caffeine intake and total vitamin $\mathrm{C}$; as well as the percentage of energy from total carbohydrates. ${ }^{38} 39$

Funding sources were assessed for all of the included prospective cohort studies. All reported funding from agency alone. ${ }^{38} 39$

\section{Total fructose intake on incident gout}

Figure 2 depicts the relationship between total fructose intake and incident gout. We identified a significant overall association between fructose intake and increased risk of incident gout with a pooled RR of 1.62 (95\% CI 1.28 to 2.03) with no evidence of significant interstudy heterogeneity $\left(\mathrm{I}^{2}=0 \%, \mathrm{p}=0.33\right)$. The pooled risk estimates came from the most-adjusted models including the adjustment for energy from total carbohydrate intake. ${ }^{38} 39$ This model allows for the effects of fructose compared with isocaloric exchange for other carbohydrates to be estimated. Both studies included in our analysis also presented results adjusted for energy from non-fructose carbohydrate and total protein to facilitate the comparison of isocaloric substitution of fructose for fat. This model resulted in more modest effect estimates (RR 1.34, 95\% CI 1.05 to 1.72 ) (see online supplementary figure S1). Pooled analysis of the least-adjusted models (adjusted for age, total energy intake, BMI and alcohol consumption in both studies) did not result in a significant association between fructose intake and gout (RR $1.10,95 \%$ CI 0.88 to 1.39 ) (see online supplementary figure S2).

\section{Total fructose intake on incident hyperuricemia}

The lack of prospective studies investigating the association between total fructose intake and incident hyperuricemia yielded by our strategy precluded testing the effect of total fructose intake on incident hyperuricemia. 


$$
\begin{array}{ll}
2,195 & \text { Reports Identified } \\
1,483 & \text { EMBASE (through to September week } 32015) \\
688 & \text { Medline (through to September week } 3 \text { 2015) } \\
19 & \text { Cochrane Library (through to September week } 32015) \\
5 & \text { Manual Searches (through to September week } 32015)
\end{array}
$$

\begin{tabular}{|l|ll|}
\hline 2,171 & Reports excluded on the basis of title and/or abstract \\
650 & Duplicate reports \\
131 & Animal reports \\
45 & In vitro reports \\
21 & Guidelines \\
860 & Studies not pertaining to either exposure (fructose intake) \\
& & or endpoints (gout or hyperuricemia) \\
52 & Commentaries \& Letters \\
61 & Case Study reports \\
23 & Conference Proceedings \\
6 & Meta-analysis reports \\
31 & Methodology Descriptions \\
183 & Review reports \\
108 & Design (cross-sectional, retrospective, intervention and \\
& acute studies including intravenous fructose administration) \\
\hline
\end{tabular}

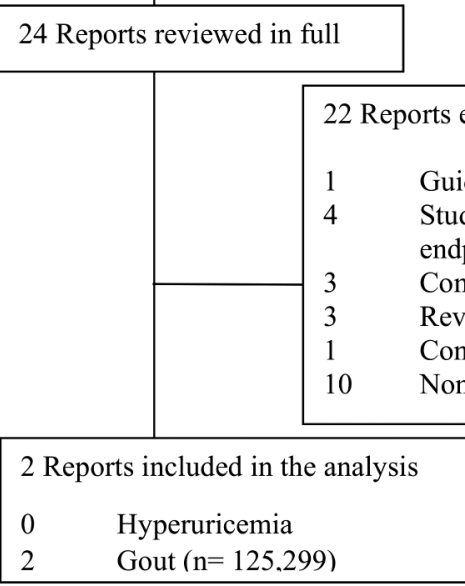

Figure 1 Summary of evidence search and selection. Flow of the literature search for the effect of fructose intake on incident gout and hyperuricemia. Of the 2195 studies initially identified, 2171 were excluded on the basis of title and abstract review. The remaining 24 studies were reviewed in full. A total of two prospective cohort studies met inclusion criteria and qualified for further analysis.

\section{Study quality}

Online supplementary table S2 shows the NOS for assessing the quality of cohort studies. All studies were considered to be high quality (NOS $\geq 6$ ).

\section{GRADE assessment}

The overall strength and quality of the evidence for the effect of fructose intake on incident gout was assessed by GRADE. Despite grading up for an observed doseresponse gradient in the studies, evidence of serious indirectness resulted in the evidence being downgraded to low quality, the default level for observational studies (see online supplementary table S3).

\section{DISCUSSION}

\section{Statement of principle findings}

We present the results of a systematic review and meta-analysis of prospective cohort studies investigating the association between total fructose intake and risk of developing hyperuricemia and gout. We identified a total of two prospective studies that assessed the relationship between fructose and gout ${ }^{38} 39$ and no prospective studies pertaining to fructose and hyperuricemia. The two studies that assessed gout included a total of 125299 participants free of gout at baseline, and 1533 identified cases of incident gout over an average of 17 years of follow-up. The results of our pooled analysis indicated that total fructose consumption was positively associated with an increased risk of developing gout by $62 \%$ when comparing extreme quantiles of fructose intake.

\section{Strengths and weaknesses of the study}

There are many strengths of our analysis pertaining to fructose and gout. The studies that were included were relatively large (125 299 participants and 1533 cases of incident gout), and both had follow-up durations in 


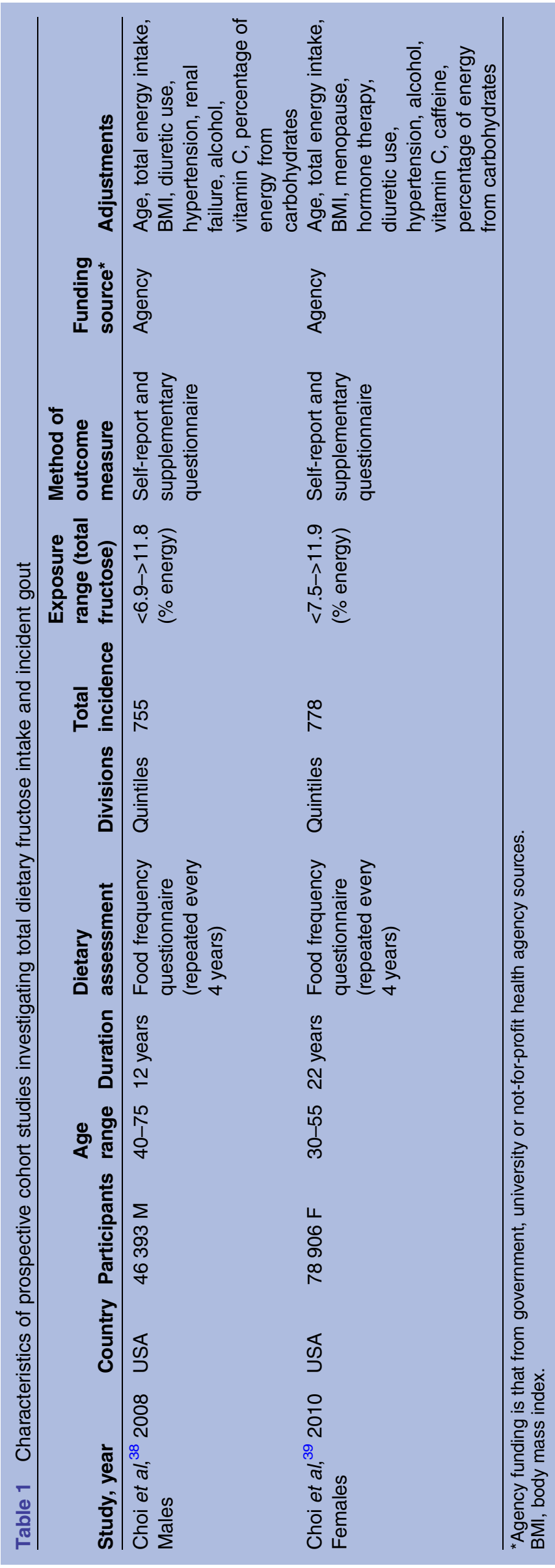

excess of 10 years (12 and 22 years). The methodologies of these two studies, including the validated FFQ used for dietary assessment and the evaluation of incident gout, were remarkably similar, and there was no evidence of interstudy heterogeneity. In both studies, repeated administration of FFQs facilitated the analyses of long-term intakes of fructose, not simply diets at baseline. Furthermore, both studies included in the analysis of gout had NOS scores $\geq 6$, indicating that they were of high quality. We also assessed the overall strength of evidence from both studies combined using the GRADE approach. However, there are many notable limitations. We were unable to test the pooled relationship between fructose intake and incident hyperuricemia due to the lack of any prospective studies investigating this association. With regard to fructose and incident gout, we only identified two prospective studies. This meant that we were unable to assess publication bias or perform sensitivity, a priori subgroup and dose-response analyses using the pooled data. Furthermore, although the number of participants included in both studies were relatively large, both cohorts were recruited in the USA, meaning that our analysis has low generalisability to other populations. Indeed, various genetic risk factors for gout have been identified ${ }^{41}$ with some ethnic groups particularly susceptible to gout, ${ }^{6}$ therefore, the results might not apply to other populations. Finally, although both studies included in this analysis adjusted for a number of potentially important confounders, the observational design of these studies precludes the inference of causation due to the possibility of residual confounders that remain unaccounted.

\section{Findings in relation to other studies}

The results of our meta-analysis support the notion that elevated fructose intake is a risk factor for the development of gout. A recent cross-sectional analysis identified a link between intake of SSBs and prevalent gout, ${ }^{42}$ and a systematic review ${ }^{43}$ of risk factors associated with gout identified fructose intake among other established dietary risk factors including alcohol, meat and seafood consumption. Dietary factors associated with a lower risk of gout include dairy, folate and coffee intake. ${ }^{43}$ Both studies included in our meta-analysis identified a significant association between SSB consumption and increased risk of gout while similar associations were not observed for diet soft drink consumption. ${ }^{38} 39$

The prevalence of gout has been found to be significantly higher in men than women in many diverse populations. ${ }^{44-46}$ Of the two studies included in our analysis of fructose and gout, one was conducted in men from the Health Professionals Follow-up Study, ${ }^{38}$ and the other was carried out in women from the Nurses' Health Study. ${ }^{39}$ In agreement with worldwide prevalence estimates, men in the Health Professionals Follow-up Study developed gout at a higher rate than women from the Nurses' Health Study. This potentially contributed to the lower effect size observed in the analysis of the 


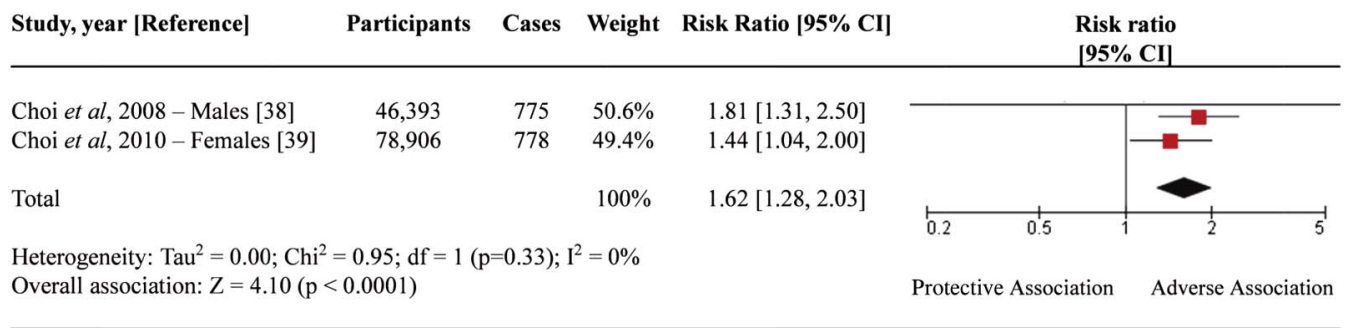

Figure 2 Fructose intake and the relative risk of gout. Forest plot of prospective cohort studies investigating the relationship between total fructose intake and incident gout. Estimates from most-adjusted multivariate models accounting for percentage of energy from total carbohydrates were used. The diamond represents the pooled effect estimate. Interstudy heterogeneity was tested using Cochran $Q$ statistic and quantified using the $\mathrm{I}^{2}$ statistic $\left(\mathrm{I}^{2} \geq 50 \%\right.$ indicative of significant heterogeneity). All results are presented as risk ratios (RR) with $95 \%$ Cls.

Nurses' Health Study despite a larger sample size and similar levels of fructose intake compared to the Health Professional Follow-up Study analysis. Although the exact mechanisms that result in differences in the rates of developing gout between the sexes have not yet been fully elucidated, the protective and uricosuric effects of female sex hormones are thought to play a role. ${ }^{47} 48$

Hyperuricemia is a major risk factor for gout and is understood to be instrumental in its development. ${ }^{1}$ Emerging evidence has also implicated hyperuricemia in the development of the metabolic syndrome, hypertension and $\mathrm{CVD}^{3}$ although these associations have not been consistently reported in studies that include only hyperuricemic individuals without gout. ${ }^{49}$ We found no prospective studies investigating fructose intake and incident hyperuricemia to support the observed association between fructose and gout. Some crosssectional analyses and clinical trials have supported the association between HFCS-sweetened beverage intake and increased levels of circulating uric acid $;{ }^{51-54}$ however, analysis of NHANES data did not support the link between fructose intake and increased risk of hyperuricemia. ${ }^{55}$ Furthermore, prospective evidence has shown that intake of SSBs, which is known to be a large contributor to total fructose intake in western populations, ${ }^{56}$ is not associated with an increased risk of incident hyperuricemia. ${ }^{52}$ These inconsistent findings highlight the need for more long-term prospective studies investigating fructose intake from all sources in order to gain a better understanding of the effects of fructose intake on risk of hyperuricemia.

\section{Meaning of study: possible explanations and implications for clinicians and policymakers}

Mechanistically, the phosphorylation of fructose is thought to lead to ATP depletion and the subsequent accumulation of $\mathrm{AMP}^{57}$ The lack of free phosphate results in the conversion of AMP to IMP, a uric acid precursor, by AMP deaminase. ${ }^{39}$ High fructose levels and this associated decrease in ATP have been shown to lead to a compensatory effect of increasing purine nucleotide synthesis, ${ }^{15}$ which can subsequently lead to the further overproduction of uric acid in the presence of additional fructose. Additionally, fructose-induced hyperinsulinemia and insulin resistance ${ }^{39} 58$ may lead to higher levels of circulating uric acid through the reduction of uric acid excretion. ${ }^{59}$ Results of our pooled analysis suggest that fructose may indeed act as a risk factor for the development of gout; however, the lack of prospective studies assessing hyperuricemia as an outcome limits our ability to attribute this association with gout to the mechanism proposed above. It remains possible that fructose intake increases the risk of developing gout through undetermined mechanisms independent of any effects on serum urate levels, although this is unlikely given the link between fructose and uric acid production $^{57}$ and the established role of elevated serum urate in the development of gout. ${ }^{2}$

Current dietary guidelines recommend a reduction in added or free sugars that include fructose intake (especially from SSBs) while also not discouraging the consumption of sugars from whole fruits and vegetables. ${ }^{60}$ While SSBs represent the largest contributor to total fructose intake in the USA, fruits and fruit products are also a significant contributor. ${ }^{56}$ Furthermore, the 2012 American College of Rheumatology Guidelines for Management of Gout recommends limited consumption of HFCS-sweetened soft drinks and energy drinks but does not mention whether fructose from other sources should be limited. ${ }^{61}$ It is clear that more prospective research investigating the effects of fructose intake and important food sources of fructose (SSBs, fruits and fruit products, grain-based products, dairy products, etc) on incident gout and hyperuricemia are necessary to better inform policymakers as they develop improved dietary guidelines for the management and prevention of these chronic conditions.

\section{CONCLUSIONS}

Our systematic review and meta-analysis of prospective cohort studies supports the association between fructose intake and increased risk of developing gout. The strength of evidence for the association between fructose consumption and risk of gout was low, as assessed by GRADE. It means that further research is likely to have a 
significant impact on our confidence in the effect estimate and is likely to change the estimate. ${ }^{25}$ Indeed, only two studies involving predominantly white health professionals were included in our analysis. Nevertheless, our results are consistent with a growing body of literature implicating fructose as a risk factor for developing gout. We were unable to identify any prospective studies investigating the effects of fructose intake on risk of developing hyperuricemia. Given that gout is on the rise and has recently been shown to affect $\sim 4 \%$ of the American population, ${ }^{4}{ }^{5}$ it is crucial that the dietary factors that may confer risk of developing gout are fully elucidated and understood. It is, therefore, imperative that more prospective studies assess the intake of fructose and its food sources in relation to gout and hyperuricemia in diverse populations to determine if and, ultimately, to what extent fructose may mediate the risk of hyperuricemia and gout.

\section{Author affiliations}

${ }^{1}$ Department of Nutritional Sciences, Faculty of Medicine, University of Toronto, Toronto, Ontario, Canada

${ }^{2}$ Toronto 3D Knowledge Synthesis and Clinical Trials Unit, Clinical Nutrition and Risk Factor Modification Centre, St. Michael's Hospital, Toronto, Ontario, Canada

${ }^{3}$ Department of Clinical Epidemiology and Biostatistics, Faculty of Health Sciences, McMaster University, Hamilton, Ontario, Canada

${ }^{4}$ Department of Medicine, Faculty of Medicine, University of Toronto, Toronto, Ontario, Canada

${ }^{5}$ Division of Endocrinology and Metabolism, St. Michael's Hospital, Toronto, Ontario, Canada

${ }^{6}$ Li Ka Shing Knowledge Institute, St. Michael's Hospital, Toronto, Ontario, Canada

${ }^{7}$ College of Pharmacy and Nutrition, University of Saskatchewan, Saskatoon, Saskatchewan, Canada

Acknowledgements The authors thank Teruko Kishibe for her help in the development of search terms used.

Contributors All authors had full access to all of the data (including statistical reports and tables) in this study and take full responsibility for the integrity of the data and the accuracy of the data analysis. RJdS, CWCK, DJAJ and JLS contributed to conception and design. JJ, SR, SBM, RJdS, TAK, LAL, TMSW, CWCK, DJAJ and JLS were involved in the analysis and interpretation of the data, contributed to critical revision of the article for important intellectual content and provided final approval of the article. JJ, SR and JLS were involved in the drafting of the article. RJdS provided statistical expertise. RJdS, CWCK, DJAJ and JLS obtained funding. SBM provided administrative, technical or logistic support. JJ, SR, SBM and RJdS were involved in collection and assembly of data. JLS is the guarantor.

Funding This work was funded by a Canadian Institutes of Health Research (CIHR) programmatic grant (funding reference number, 129920) through the Canada-wide Human Nutrition Trialists' Network (NTN) and an unrestricted grant from the Calorie Control Council. The Diet, Digestive tract, and Disease (3-D) Centre, funded through the Canada Foundation for Innovation (CFI) and the Ministry of Research and Innovation's Ontario Research Fund (ORF), provided the infrastructure for the conduct of this project. RJdS was funded by a CIHR Postdoctoral Fellowship Award. DJAJ was funded by the Government of Canada through the Canada Research Chair Endowment. JLS was funded by a PSI Graham Farquharson Knowledge Translation Fellowship, Canadian Diabetes Association (CDA) Clinician Scientist award, CIHR INMD/ CNS New Investigator Partnership Prize and Banting \& Best Diabetes Centre Sun Life Financial New Investigator Award.

Disclaimer None of the sponsors had a role in any aspect of the present study, including design and conduct of the study; collection, management, analysis and interpretation of the data and preparation, review, approval of the manuscript or decision to publish.

Competing interests RJdS has served as an external resource person to the World Health Organization (WHO) Nutrition Guidelines Advisory Group on trans fats and saturated fats. The WHO paid for his travel and accommodation to attend meetings from 2012-2015 to present and discuss this work. He has also done contract research for the Canadian Institutes of Health Research's Institute of Nutrition, Metabolism, and Diabetes, Health Canada, and the World Health Organization for which he received remuneration. He has held a grant from the Canadian Foundation for Dietetic Research as a principal investigator, and is a co-investigator on several funded team grants from Canadian Institutes of Health Research. TMSW is a part owner and the President of Glycemic Index Laboratories, Toronto, Ontario, Canada and has authored several popular diet books on the glycemic index for which he has received royalties from Phillipa Sandall Publishing Services and CABI Publishers. He has received consultant fees, honoraria, travel funding or research support from or served on the scientific advisory board for CIHR, CDA Dairy Farmers of Canada, McCain Foods, Temasek Polytechnic, Northwestern University, Royal Society of London, Glycemic Index Symbol program, CreaNutrition AG, McMaster University, Canadian Society for Nutritional Sciences, National Sports and Conditioning Association, Faculty of Public Health and Nutrition-Autonomous University of Nuevo Leon, Diabetes and Nutrition Study Group of the European Association for the Study of Diabetes. CWCK has received research support from the Advanced Foods and Material Network, Agrifoods and Agriculture Canada, the Almond Board of California, the American Pistachio Growers, Barilla, the California Strawberry Commission, the Calorie Control Council, CIHR, the Canola Council of Canada, Hain Celestial, the International Tree Nut Council Nutrition Research and Education Foundation, Kellogg, Kraft, Loblaw Companies, Orafti, Pulse Canada, Saskatchewan Pulse Growers, Solae and Unilever. He has received travel funding, consultant fees and/or honoraria from Abbott Laboratories, the Almond Board of California, the American Peanut Council, the American Pistachio Growers, Barilla, Bayer, the Canola Council of Canada, the Coca-Cola Company, Danone, General Mills, the International Tree Nut Council Nutrition Research and Education Foundation, Kellogg, Loblaw Companies, the Nutrition Foundation of Italy, Oldways Preservation Trust, Orafti, Paramount Farms, the Peanut Institute, PepsiCo, Pulse Canada, Sabra Dipping, Saskatchewan Pulse Growers, Solae, Sun-Maid, Tate and Lyle and Unilever. He is on the Clinical Practice Guidelines Expert Committee for Nutrition Therapy of the European Association for the Study of Diabetes (EASD) and has served on the scientific advisory board for the Almond Board of California, INC International Nut and Dried Fruit Council, Oldways Preservation Trust, Paramount Farms and Pulse Canada He is a member of the International Carbohydrate Quality Consortium (ICQC), Executive Board Member of the Diabetes and Nutrition Study Group (DNSG) of the EASD, and Director of the Toronto 3D Knowledge Synthesis and Clinical Trials foundation. DJAJ has received research grants from Saskatchewan Pulse Growers, the Agricultural Bioproducts Innovation Program through the Pulse Research Network, the Advanced Foods and Material Network, Loblaw Companies Ltd., Unilever, Barilla, the Almond Board of California, Agriculture and Agri-food Canada, Pulse Canada, Kellogg's Company, Canada, Quaker Oats, Canada, Procter \& Gamble Technical Centre Ltd., Bayer Consumer Care, Springfield, NJ, Pepsi/Quaker, INC International Nut and Dried Fruit Council, Soy Foods Association of North America, the Coca-Cola Company (investigator initiated, unrestricted grant), Solae, Haine Celestial, the Sanitarium Company, Orafti, the International Tree Nut Council Nutrition Research and Education Foundation, the Peanut Institute, the Canola and Flax Councils of Canada, the Calorie Control Council, the CIHR, the Canada Foundation for Innovation and the Ontario Research Fund. He has been on the speaker's panel, served on the scientific advisory board and/or received travel support and/or honoraria from the Almond Board of California, Canadian Agriculture Policy Institute, Loblaw Companies Ltd, the Griffin Hospital (for the development of the NuVal scoring system, the Coca-Cola Company, EPICURE, Danone, Saskatchewan Pulse Growers, Sanitarium Company, Orafti, the Almond Board of California, the American Peanut Council, the International Tree Nut Council Nutrition Research and Education Foundation, the Peanut Institute, Herbalife International, Pacific Health Laboratories, Nutritional Fundamental for Health, Barilla, Metagenics, Bayer Consumer Care, Unilever Canada and Netherlands, Solae, Kellogg, 
Quaker Oats, Procter \& Gamble, the Coca-Cola Company, the Griffin Hospital, Abbott Laboratories, the Canola Council of Canada, Dean Foods, the California Strawberry Commission, Haine Celestial, PepsiCo, the Alpro Foundation, Pioneer Hi-Bred International, DuPont Nutrition and Health, Spherix Consulting and WhiteWave Foods, the Advanced Foods and Material Network, the Canola and Flax Councils of Canada, the Nutritional Fundamentals for Health, Agri-Culture and Agri-Food Canada, the Canadian Agri-Food Policy Institute, Pulse Canada, the Saskatchewan Pulse Growers, the Soy Foods Association of North America, the Nutrition Foundation of Italy (NFI), NutraSource Diagnostics, the McDougall Program, the Toronto Knowledge Translation Group (St. Michael's Hospital), the Canadian College of Naturopathic Medicine, The Hospital for Sick Children, the Canadian Nutrition Society (CNS), the American Society of Nutrition (ASN), Arizona State University, Paolo Sorbini Foundation and the Institute of Nutrition, Metabolism and Diabetes. He received an honorarium from the United States Department of Agriculture to present the 2013 W.O. Atwater Memorial Lecture. He received the 2013 Award for Excellence in Research from the International Nut and Dried Fruit Council. He received funding and travel support from the Canadian Society of Endocrinology and Metabolism to produce mini cases for the CDA. He is a member of the ICQC. His wife, ALJ, is a director and partner of Glycemic Index Laboratories, Inc., and his sister received funding through a grant from the St. Michael's Hospital Foundation to develop a cookbook for one of his studies. JLS has received research support from the CIHR, American Society of Nutrition (ASN), CDA, Banting \& Best Diabetes Centre (BBDC), Calorie Control Council, The Coca-Cola Company (investigator initiated, unrestricted), Dr Pepper Snapple Group (investigator initiated, unrestricted), Pulse Canada INC International Nut and Dried Fruit Council, and The Tate and Lyle Nutritional Research Fund at the University of Toronto. He has received travel funding, speaker fees and/or honoraria from He has received speaker fees and/or honoraria from the CDA, CNS, University of Alabama at Birmingham, Abbott Laboratories, Canadian Sugar Institute, Dr. Pepper Snapple Group, The Coca-Cola Company, Dairy Farmers of Canada, NFI, C3 Collaborating for Health, WhiteWave Foods, Rippe Lifestyle, mdBriefcase, Alberta Milk, FoodMinds LLC, Memac Ogilvy \& Mather LLC, PepsiCo, and Pulse Canada. He has ad hoc consulting arrangements with Winston \& Strawn LLP, Perkins Coie LLP and Tate \& Lyle. He is a member of the European Fruit Juice Association Scientific Expert Panel. He is on the Clinical Practice Guidelines Expert Committees of the CDA, EASD, and Canadian Cardiovascular Society (CCS), as well as an expert writing panel of the ASN. He serves as an unpaid scientific advisor for the Food, Nutrition, and Safety Program (FNSP) and the Technical Committee on Carbohydrates of the International Life Science Institute (ILSI) North America. He is a member of the ICQC, Executive Board Member of the Diabetes and Nutrition Study Group (DNSG) of the EASD, and Director of the Toronto 3D Knowledge Synthesis and Clinical Trials foundation. His wife is an employee of Unilever Canada. JJ, SR, SBM, and TK declare no competing interests related to this manuscript.

Provenance and peer review Not commissioned; externally peer reviewed.

Data sharing statement No additional data are available.

Open Access This is an Open Access article distributed in accordance with the Creative Commons Attribution Non Commercial (CC BY-NC 4.0) license, which permits others to distribute, remix, adapt, build upon this work noncommercially, and license their derivative works on different terms, provided the original work is properly cited and the use is non-commercial. See: http:// creativecommons.org/licenses/by-nc/4.0/

\section{REFERENCES}

1. Richette P, Bardin T. Gout. Lancet 2010;375:318-28.

2. Schumacher HR Jr. The pathogenesis of gout. Cleve Clin J Med 2008;75(Suppl 5):S2-4.

3. Grassi D, Ferri L, Desideri G, et al. Chronic hyperuricemia, uric acid deposit and cardiovascular risk. Curr Pharm Des 2013;19:2432-8.

4. Zhu Y, Pandya BJ, Choi HK. Prevalence of gout and hyperuricemia in the US general population: The National Health and Nutrition Examination Survey 2007-2008. Arthritis Rheum 2011;63:3136-41.

5. Arromdee E, Michet CJ, Crowson CS, et al. Epidemiology of gout: is the incidence rising? J Rheumatol 2002;29:2403-6.

6. Kuo CF, Grainge MJ, Zhang W, et al. Global epidemiology of gout: prevalence, incidence and risk factors. Nat Rev Rheumatol 2015;11:649-62.

7. Aune D, Norat T, Vatten LJ. Body mass index and the risk of gout: a systematic review and dose-response meta-analysis of prospective studies. Eur J Nutr 2014;53:1591-601.

8. Wang $\mathrm{M}$, Jiang $\mathrm{X}, \mathrm{Wu} \mathrm{W}$, et al. A meta-analysis of alcohol consumption and the risk of gout. Clin Rheumatol 2013;32:1641-8.

9. Choi HK, Atkinson K, Karlson EW, et al. Purine-rich foods, dairy and protein intake, and the risk of gout in men. $N$ Engl $J$ Med 2004;350:1093-103.

10. Choi HK, Liu S, Curhan G. Intake of purine-rich foods, protein, and dairy products and relationship to serum levels of uric acid: the Third National Health and Nutrition Examination Survey. Arthritis Rheum 2005;52:283-9.

11. Kedar E, Simkin PA. A perspective on diet and gout. Adv Chronic Kidney Dis 2012;19:392-7.

12. Rho YH, Zhu Y, Choi HK. The epidemiology of uric acid and fructose. Semin Nephrol 2011;31:410-19.

13. Hess J, Latulippe ME, Ayoob K, et al. The confusing world of dietary sugars: definitions, intakes, food sources and international dietary recommendations. Food Funct 2012;3:477-86.

14. Bray GA, Nielsen SJ, Popkin BM. Consumption of high-fructose corn syrup in beverages May play a role in the epidemic of obesity. Am J Clin Nutr 2004;79:537-43.

15. Raivio KO, Becker A, Meyer LJ, et al. Stimulation of human purine synthesis de novo by fructose infusion. Metab Clin Exp 1975;24:861-9.

16. Stirpe F, Della Corte E, Bonetti E, et al. Fructose-induced hyperuricaemia. Lancet 1970;2:1310-11.

17. Cox CL, Stanhope KL, Schwarz JM, et al. Consumption of fructosebut not glucose-sweetened beverages for 10 weeks increases circulating concentrations of uric acid, retinol binding protein-4, and gamma-glutamyl transferase activity in overweight/obese humans. Nutr Metab (Lond) 2012:9:68.

18. Ha V, Jayalath $\mathrm{VH}, \mathrm{Cozma} \mathrm{Al}$, et al. Fructose-containing sugars, blood pressure, and cardiometabolic risk: a critical review. Cur Hypertens Rep 2013;15:281-97.

19. Wang DD, Sievenpiper JL, de Souza RJ, et al. The effects of fructose intake on serum uric acid vary among controlled dietary trials. J Nutr 2012;142:916-23.

20. Higgins JPT, Greenn S, Collaboration C. Cochrane handbook for systematic reviews of interventions. Chichester, UK; Hoboken (NJ): Wiley-Blackwell, 2008

21. Stroup DF, Berlin JA, Morton SC, et al. Meta-analysis of observational studies in epidemiology: a proposal for reporting. Meta-analysis Of Observational Studies in Epidemiology (MOOSE) group. JAMA 2000;283:2008-12.

22. Wells GA, Shea B, O'Connell D, et al. The Newcastle-Ottawa Scale (NOS) for assessing the quality of nonrandomised studies in meta-analyses. http://www.ohri.ca/programs/clinical_epidemiology/ oxford.asp

23. Guyatt $G$, Oxman AD, Akl EA, et al. GRADE guidelines: 1. Introduction-GRADE evidence profiles and summary of findings tables. J Clin Epidemiol 2011;64:383-94.

24. Guyatt GH, Oxman AD, Kunz R, et al. GRADE guidelines: 2. Framing the question and deciding on important outcomes. J Clin Epidemiol 2011;64:395-400.

25. Balshem $\mathrm{H}$, Helfand $\mathrm{M}$, Schunemann $\mathrm{HJ}$, et al. GRADE guidelines: 3. Rating the quality of evidence. J Clin Epidemiol 2011;64:401-6.

26. Guyatt GH, Oxman AD, Vist G, et al. GRADE guidelines: 4. Rating the quality of evidence-study limitations (risk of bias). J Clin Epidemiol 2011;64:407-15.

27. Guyatt $\mathrm{GH}$, Oxman AD, Montori V, et al. GRADE guidelines: 5. Rating the quality of evidence-publication bias. J Clin Epidemiol 2011;64:1277-82

28. Guyatt $\mathrm{GH}$, Oxman AD, Kunz R, et al. GRADE guidelines: 6 . Rating the quality of evidence-imprecision. J Clin Epidemiol 2011;64:1283-93.

29. Guyatt $\mathrm{GH}$, Oxman AD, Kunz R, et al. GRADE guidelines: 7. Rating the quality of evidence-inconsistency. J Clin Epidemiol 2011;64:1294-302.

30. Guyatt GH, Oxman AD, Kunz R, et al. GRADE guidelines: 8. Rating the quality of evidence-indirectness. J Clin Epidemiol 2011;64:1303-10

31. Guyatt $\mathrm{GH}$, Oxman AD, Sultan S, et al. GRADE guidelines: 9. Rating up the quality of evidence. $J$ Clin Epidemiol 2011;64:1311-16.

32. Brunetti M, Shemilt I, Pregno S, et al. GRADE quidelines: 10 Considering resource use and rating the quality of economic evidence. J Clin Epidemiol 2013;66:140-50.

33. Guyatt $\mathrm{G}$, Oxman AD, Sultan $\mathrm{S}$, et al. GRADE guidelines: 11 Making an overall rating of confidence in effect estimates for a single 
outcome and for all outcomes. J Clin Epidemiol 2013;66:151-7.

34. Guyatt GH, Oxman AD, Santesso N, et al. GRADE guidelines: 12 Preparing summary of findings tables-binary outcomes. J Clin Epidemiol 2013:66:158-72.

35. Guyatt GH, Thorlund K, Oxman AD, et al. GRADE guidelines: 13. Preparing summary of findings tables and evidence profiles-continuous outcomes. J Clin Epidemiol 2013;66:173-83.

36. The Cochrane Collaboration. The generic inverse variance method. http://cfgd.cochrane.org/search/google-appliance/generic\%20inverse \%20variance\%20method (accessed 28 Jan 2016).

37. Higgins JP, Thompson SG. Quantifying heterogeneity in a meta-analysis. Stat Med 2002;21:1539-58.

38. Choi HK, Curhan G. Soft drinks, fructose consumption, and the risk of gout in men: prospective cohort study. BMJ 2008;336:309-12.

39. Choi HK, Willett W, Curhan G. Fructose-rich beverages and risk of gout in women. JAMA 2010;304:2270-8.

40. Wallace SL, Robinson H, Masi AT, et al. Preliminary criteria for the classification of the acute arthritis of primary gout. Arthritis Rheum 1977;20:895-900.

41. Reginato AM, Mount DB, Yang I, et al. The genetics of hyperuricaemia and gout. Nat Rev Rheumatol 2012;8:610-21.

42. Batt C, Phipps-Green AJ, Black MA, et al. Sugar-sweetened beverage consumption: a risk factor for prevalent gout with SLC2A9 genotype-specific effects on serum urate and risk of gout. Ann Rheum Dis 2014;73:2101-6.

43. Singh JA, Reddy SG, Kundukulam J. Risk factors for gout and prevention: a systematic review of the literature. Curr Opin Rheumatol 2011;23:192-202.

44. Singh JA. Racial and gender disparities among patients with gout. Curr Rheumatol Rep 2013;15:307.

45. Winnard D, Wright C, Taylor WJ, et al. National prevalence of gout derived from administrative health data in Aotearoa New Zealand. Rheumatology (Oxford) 2012;51:901-9.

46. Smith E, Hoy D, Cross M, et al. The global burden of gout: estimates from the Global Burden of Disease 2010 study. Ann Rheum Dis 2014;73:1470-6.

47. Hak AE, Choi HK. Menopause, postmenopausal hormone use and serum uric acid levels in US women-the Third National Health and Nutrition Examination Survey. Arthritis Res Ther 2008;10:R116.

48. Hak AE, Curhan GC, Grodstein F, et al. Menopause, postmenopausal hormone use and risk of incident gout. Ann Rheum Dis 2010;69:1305-9.
49. Abeles AM. Hyperuricemia, gout, and cardiovascular disease: an update. Curr Rheumatol Rep 2015;17:13.

50. van Durme $C$, van Echteld IA, Falzon $L$, et al. Cardiovascular risk factors and comorbidities in patients with hyperuricemia and/or gout: a systematic review of the literature. J Rheumatol Suppl 2014;92:9-14

51. Choi JW, Ford ES, Gao X, et al. Sugar-sweetened soft drinks, diet soft drinks, and serum uric acid level: the Third National Health and Nutrition Examination Survey. Arthritis Rheum 2008;59:109-16.

52. Bomback AS, Derebail VK, Shoham DA, et al. Sugar-sweetened soda consumption, hyperuricemia, and kidney disease. Kidney Int 2010;77:609-16.

53. Stanhope KL, Medici V, Bremer AA, et al. A dose-response study of consuming high-fructose corn syrup-sweetened beverages on lipid/ lipoprotein risk factors for cardiovascular disease in young adults. Am J Clin Nutr 2015;101:1144-54.

54. Meneses-Leon J, Denova-Gutiérrez E, Castañón-Robles S, et al. Sweetened beverage consumption and the risk of hyperuricemia in Mexican adults: a cross-sectional study. BMC Public Health 2014; $14: 445$

55. Sun SZ, Flickinger BD, Williamson-Hughes PS, et al. Lack of association between dietary fructose and hyperuricemia risk in adults. Nutr Metab (Lond) 2010;7:16.

56. Marriott BP, Cole N, Lee E. National estimates of dietary fructose intake increased from 1977 to 2004 in the United States. J Nutr 2009;139:1228S-35S.

57. Choi HK, Mount DB, Reginato AM, et al. Pathogenesis of gout. Ann Intern Med 2005;143:499-516.

58. Wu T, Giovannucci E, Pischon T, et al. Fructose, glycemic load, and quantity and quality of carbohydrate in relation to plasma C-peptide concentrations in US women. Am J Clin Nutr 2004;80:1043-9.

59. Quiñones Galvan A, Natali A, Baldi $S$, et al. Effect of insulin on uric acid excretion in humans. Am J Physiol 1995;268(Pt 1):E1-5.

60. US Department of Health and Human Services; US Department of Agriculture. Scientific report of the 2015 Dietary Guidelines Advisory Committee. Washington (DC): US Government Printing Office, 2015.

61. Khanna D, Fitzgerald JD, Khanna PP, et al. 2012 American College of Rheumatology guidelines for management of gout. Part 1: systematic nonpharmacologic and pharmacologic therapeutic approaches to hyperuricemia. Arthritis Care Res (Hoboken) 2012;64:1431-46. 